\title{
THE FIRST STAGE LARVA OF CUTEREBRA AMERICANA (FABR.) (DIPTERA; OESTRIDE).
}

\author{
By G. F. Ferris, \\ Stanford University, California.
}

There appears to be but little information concerning the first stage larvæ of any species of Oestridæ, the only very detailed figures that I have seen being those given by Hadwen and Cameron ${ }^{1}$ of the larvæ of three species of Gastrophilus. I have been fortunate enough to secure some notes on the first stage of Cuterebra americana (Fabr.) (det. Aldrich) and present them in order that they may not be lost, brief though they are.

A female of this species was taken in flight at Palo Alto, Calif., on October 8 and was confined in a glass jar. On this same day (perhaps partially on the following) this female deposited from 100 to 150 eggs which were placed singly and were attached to the glass by a glue so powerful that the eggs could not be detached without being destroyed. Unfortunately no notes were kept as to the shape of the eggs.

The eggs began to hatch on October 22. In the case of the species discussed by Hadwen and Cameron there has existed some doubt as to whether the eggs hatch normally without the stimulus of moisture, heat and friction, although these authors found that at least a certain percentage do. In the case of Cuterebra americana these factors seem to have no place as apparently all the eggs hatched.

The first stage larvæ are extremely active. Clinging to the empty egg shells they waved the head energetically about in the air and some of them deserted the egg shells and moved about, progression being accomplished by means of a looping movement much like that of a Geometrid caterpillar. No notes were kept as to the length of time that the larvæ lived without food.

\section{Description of the Larva.}

Length (flattened on slide) $1.4 \mathrm{~mm}$.; body fusiform, tapering at both ends (Fig. A). Posterior extremity ending in a single flat lobe

\footnotetext{
1 Hadwen, S. and Cameron, A. E. A Contribution to the Knowledge of the Bot-Flies, Gastrophilus intestinalis DeG., G. homorrhoidalis L. and G. nasalis L. Bull. Ent. Res., vol. 9, pt. 2. pp. 91-106, figs. (1918).
} 
which projects well beyond the spiracles and is slightly emarginate at the tip. The actual number of segments cannot be determined from the mounts, but there are in all nine transverse series of posteriorly pointing denticles. The anteriormost series is close to the anterior end of the body and is composed of very small denticles. The second to fourth series are each composed of a single row of flat denticles, the points of which are directed toward the median line and end in a recurved hook (Fig. B). Between each two of these

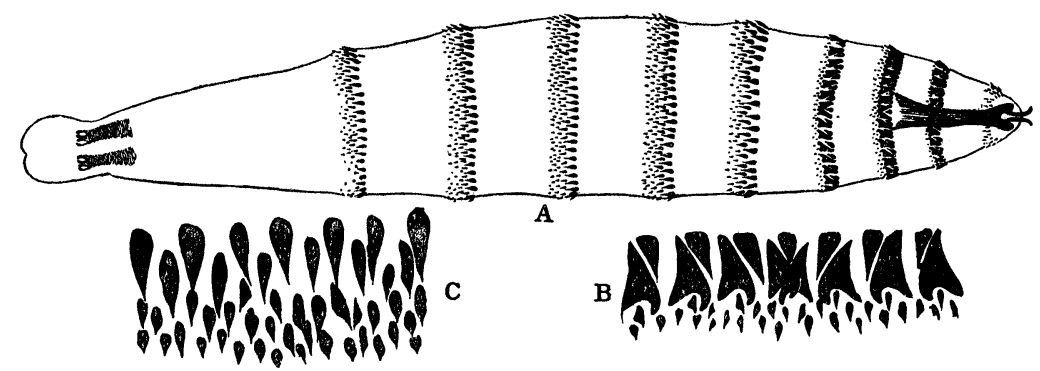

Fig. 1. Cuterebra americana, first stage: A, entire larva only the bases of the tracheal trunks are indicated; $\mathrm{B}$, denticles from third series at the median line; C, denticles from fifth series.

denticles are smaller sharply pointed denticles and behind them are a varying number of still smaller, sharp denticles. The remaining series are all composed of numerous sharply pointed denticles, of which the anteriormost are much larger than the others (Fig. C). The cephalopharyngeal apparatus extends back to the anterior margin of the third series.

Note.-The above description is based upon specimens that have been cleared, stained and mounted on a slide. 

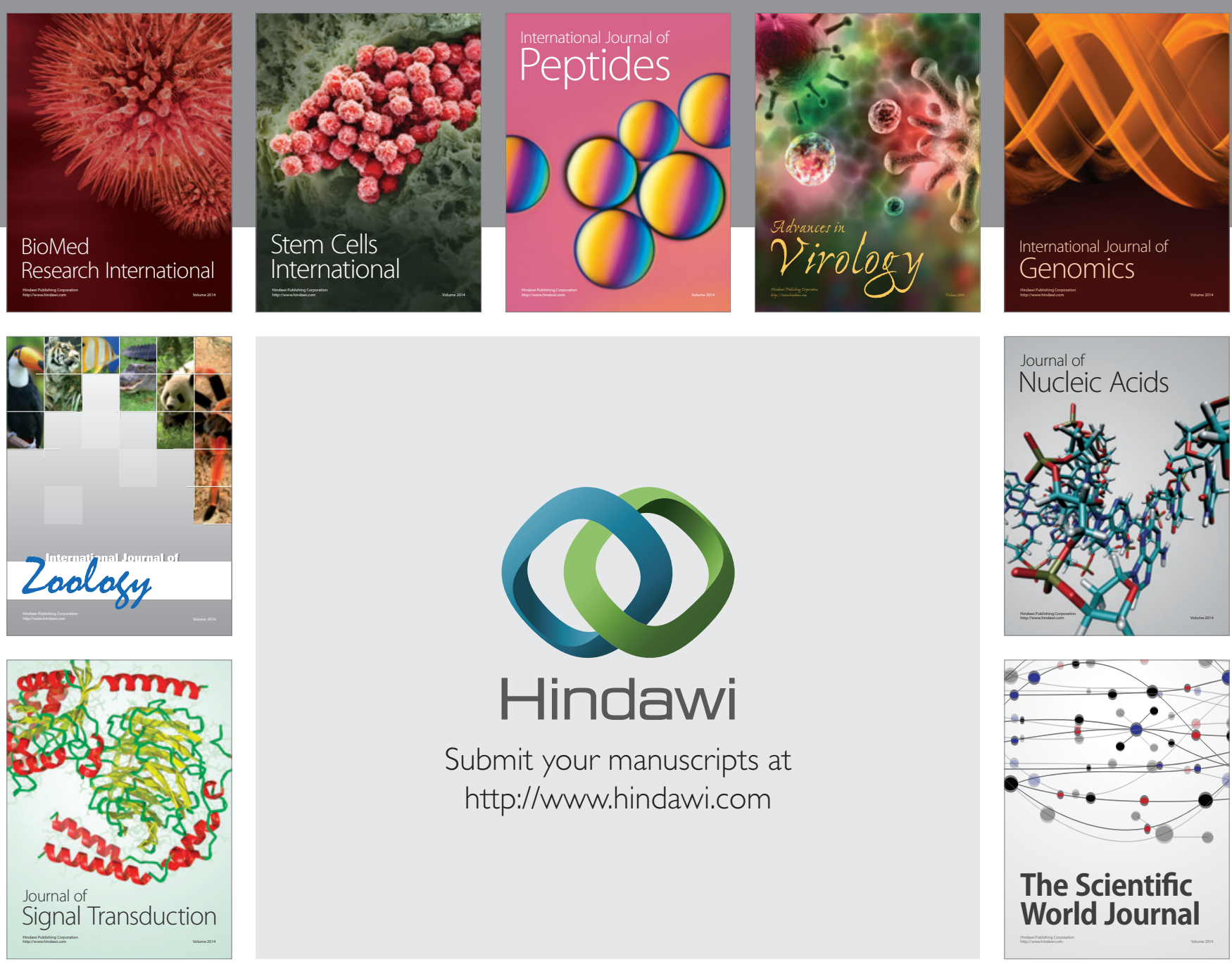

Submit your manuscripts at

http://www.hindawi.com
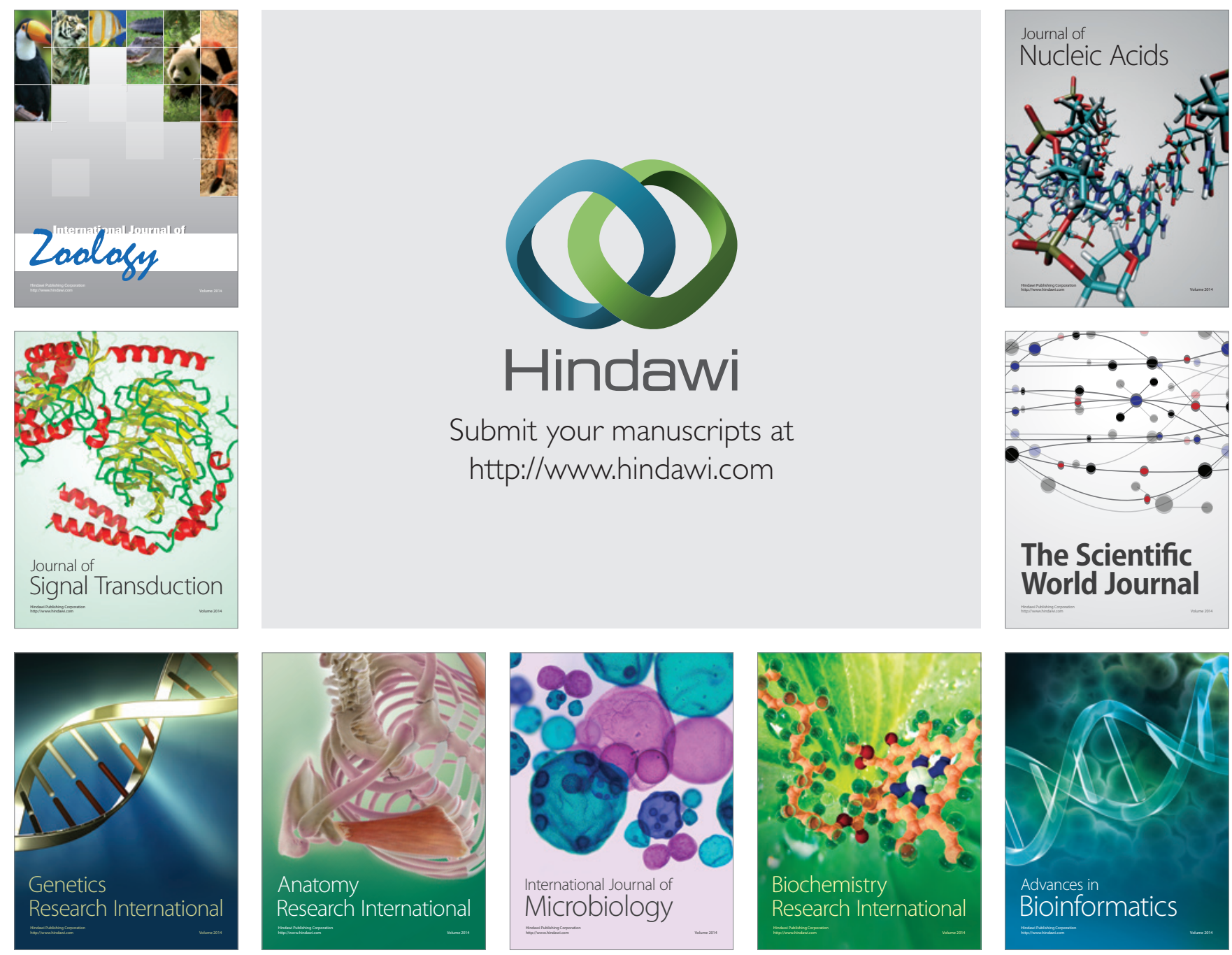

The Scientific World Journal
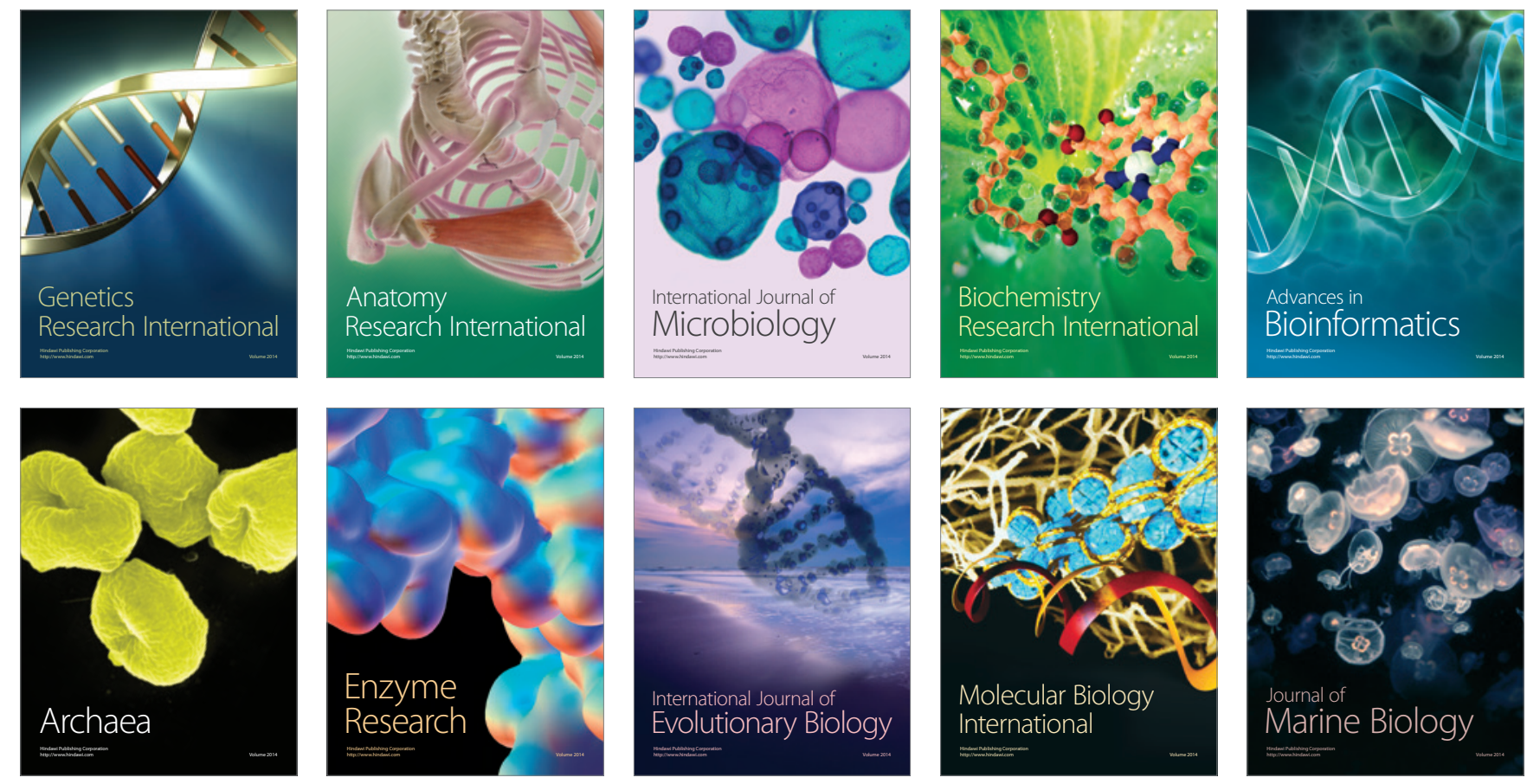